\title{
Remembering John C. Loehlin: 'Our Field Has Lost a Lion'/Twin Research Reviews: Cognitive Skills and Social Mobility, Risk of Arachnoid Hemorrhage, Heritability of Dental Traits, and Twin-to- Twin Transfusion Syndrome/Media Reports: Identical Twins With Different Health Histories, Twins Born 97 Days Apart, Retiring Twin Tennis Players, TikTok Twins and Twin Reality Stars
}

\author{
Nancy L. Segal \\ Department of Psychology, California State University, Fullerton, CA, USA
}

\begin{abstract}
John C. Loehlin, professor of psychology at the University of Texas, at Austin, passed away on August 9, 2020. John was 94 years of age. He will be remembered for his seminal contributions that have furthered the field of twin research in so many ways. An overview of his career is presented, with fond memories from his son and several colleagues. This tribute is followed by reviews of twin research on cognitive skills and social mobility, risk of subarachnoid hemorrhage, heritability of selected dental traits and twin-to-twin transfusion syndrome. Finally, twin-related topics of human interest include identical twins with different health histories, twins born 97 days apart, retiring twin tennis players, TikTok twins and twin reality stars.
\end{abstract}

First Published online 3 December 2020

Remembering John C. Loehlin: 'Our Field Has Lost a Lion' the name John C. Loehlin is synonymous with outstanding contributions to the field of twin research (see Figure 1). Anyone who studies twins would be familiar with John's landmark study of 850 pairs of twins who took the National Merit Scholarship Qualifying Test (Loehlin \& Nichols, 1976). They would know his stunning twin research on genetics, evolution and personality (Bouchard \& Loehlin, 2001), his insightful appraisals of genetic influences on general intelligence (Loehlin, 2002), his seminal work on twin methodology (Loehlin, 2004) and his influential studies of sex differences using opposite-sex twins (Loehlin \& Martin, 2000). It is not surprising that when John's son, James, sent word of his father's passing to the International Society for Twin Studies (ISTS), members forwarded warm thoughts and outstanding tributes in remembrance of their late colleague. The subtitle I have chosen for this article was contributed by Dr Gregory Carey at the University of Colorado, at Boulder, and expresses it best: 'Our field has lost a lion'.

In this article I will present an overview of John's life as a friend and colleague. I will also include the tributes that I received and provide some memories of my own. The information in this article

Author for correspondence: Nancy Segal. Email: nsegal@fullerton.edu

Cite this article: Segal NL. (2020) Remembering John C. Loehlin: 'Our Field Has Lost a Lion'/Twin Research Reviews: Cognitive Skills and Social Mobility, Risk of Arachnoid Hemorrhage, Heritability of Dental Traits, and Twin-to-Twin Transfusion Syndrome/ Media Reports: Identical Twins With Different Health Histories, Twins Born 97 Days Apart, Retiring Twin Tennis Players, TikTok Twins and Twin Reality Stars. Twin Research and Human Genetics 23: 359-362, https://doi.org/10.1017/thg.2020.79 was largely drawn from John's curriculum vitae and an obituary, both provided by his son, James.

John C. Loehlin was born on January 13, 1926 in Ferozepur, India. His parents, Clinton and Eunice Loehlin, were Presbyterian missionaries who raised him in the Punjab area of northern India. John attended the Woodstock School, an international coeducational residential facility in Landour (Woodstock School, 2020), graduating in 1942. His next transition was to the USA where he earned a Bachelor of Arts degree at Harvard University, in English, in 1947. During the years 1947-1953, John variously worked in the research department of an advertising firm, enrolled in the psychology doctoral program at the University of California-Berkeley, entered the USA Navy, then returned to Berkeley to complete his PhD degree in 1957.

John's first academic positions were as an instructor and an assistant professor at the University of Nebraska (1957-1964). In 1964, he relocated to the University of Texas at Austin, as a visiting associate professor of psychology. John steadily made his way up the academic ranks to full professor of psychology and computer sciences in 1969. He chaired the psychology department at the University of Texas between 1979 and 1983. He became Professor Emeritus from 1992 until the time of his passing. However, John also held a number of prestigious positions throughout these years - for example, Consultant to the National Merit Scholarship Corporation, Fellow at the Center for Advanced Study in the Behavioral Sciences, President and Treasurer of the Behavior Genetics Association and President of the Society for Multivariate Experimental Psychology.

John received a number of academic awards and honors. He was a Fellow of the American Association for the Advancement 


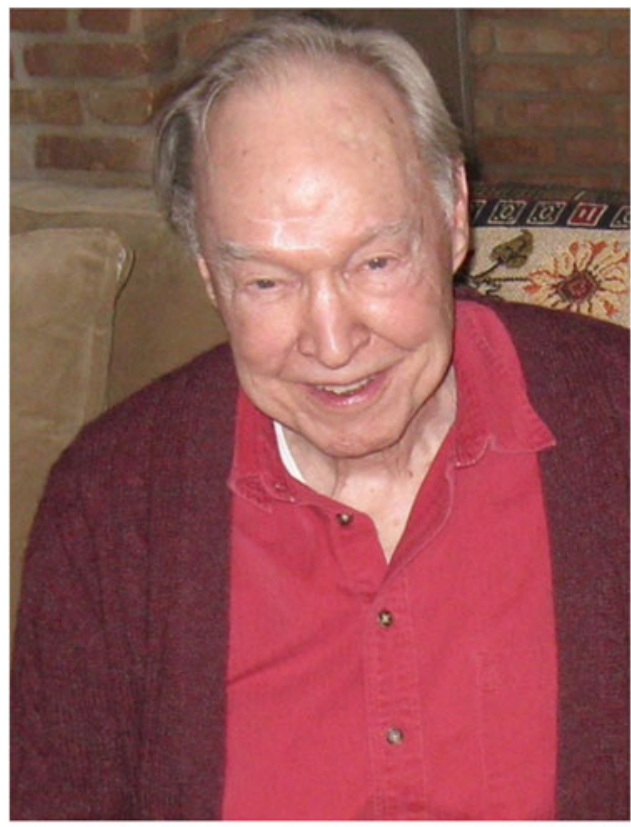

Fig. 1. John C. Loehlin. Courtesy: John's son James

of Science and a Charter Fellow of the American Psychological Society. He was also the recipient of the coveted Dobzhansky Award from the Behavior Genetics Association in 1991. Subsequent to his retirement, a Festschrift was arranged in his honor as part of the annual Behavior Genetics Association meeting, held in 2011. The proceedings from this event were published in a special issue of the journal Behavior Genetics in 2014 (Waldman \& Turkheimer, 2014). The various contributions to the Festschrift reflected the different topics and issues on which John had worked during the course of his career. They include contributions to computer models of personality and multivariate statistics and multivariate behavior genetic analyses (John McArdle), measures of rearing environmental similarity and tests of the equal environments assumption in twin studies (Devon LoParo and Irwin Waldman), evolutionary explanations for the structure of mental abilities and a general cognitive ability factor (Thomas J, Bouchard, Jr.), longitudinal behavior genetic analysis of continuity and change in alcohol use (Matt McGue and colleagues), Cholesky decomposition to test alternative models for the causal relations among negative emotionality, stressful life events, and depression (Liz DiLalla and Marcella Reitschel, and Nick Martin), multivariate behavior genetic models (i.e. the common vs. the independent pathway models; Sanja Franic and Dorret Boomsma), gene-environment correlation (Robert Plomin) and the detection and analysis of $\mathrm{G}$ by $\mathrm{E}$ interaction for complex traits (Lindon Eaves).

\section{Tributes from Colleagues}

I am grateful to those colleagues who shared their reflections and recollections of John. They are reproduced below.

One of our very best, both intellectually and personally. Thomas J. Bouchard, Jr.

This is a great loss for behavior genetics. I assume you'll [Nancy] get plenty of comments, but I just want to say that he was such a gentleman and so incredibly intelligent. We had a wonderful conversation one year at BGA even though we had just met. I have always harbored positive feelings for him because he made our conversation so comfortable and interesting. Lisabeth DiLalla

I just received this sad news about John Loehlin. Our field has lost a lion. Greg Carey

I echo Greg's sentiment; John was a giant in the field, the first to explore many of the topics that have preoccupied us since, especially multivariate genetic analysis. I was flattered that late in life we started to collaborate and published 20 papers together since 1998, the last as recently as 2018. I also found out late about his talent as a poet and bought and enjoyed his 'Poems of a young man' - wry, economical, quite Thurberesque. I was thinking only last week that I hadn't heard from him in a while and ought to email him; too late alas. John was unfailingly courteous and scholarly - a true gentlemen. I shall miss him. My condolences to you [James, John's son] and to all your family. Best wishes. Nick Martin

It is often the case that we discover new things about a person only after their passing. Aside from learning that John had been born and raised in India, I learned that he had authored two published volumes of original poetry (Loehlin, 2010a, 2010b), one of them mentioned in Nick Martin's remarks above. I also have my own recollections of interactions with John. John was one of two reviewers of my proposal for a book chronicling the history of the Minnesota Study of Twins Reared Apart. Harvard University Press approved the proposal and the result was Born Together - Reared Apart: The Landmark Minnesota Twin Study (Segal, 2012). Of course, I did not know that John was one of the reviewers until my editor mentioned it months later. Knowing that, I contacted John several times with questions to which he always provided instructive answers. I also remember chatting with John while researching and writing a book about two sets of monozygotic male twins from Colombia, South America who were accidentally switched at birth (Segal \& Montoya, 2018). John was enthusiastic and offered several helpful comments. Finally, I always made an effort to attend John's presentations at Behavior Genetics Association meetings because they were informative and well-reasoned.

$$
* * * * *
$$

John is survived by his wife, Marjorie Leafdale Loehlin, his children, Jennifer Ann Loehlin and James Norris Loehlin and their respective partners Mike Mashl and Laurel Loehlin. John is also survived by his sister, Mildred Loehlin Harris, of Arizona, his brother, James Herbert Loehlin, of Massachusetts, and their spouses, Richard Harris and Allie Loehlin. He is additionally survived by his brother-in-law, Byron Shafer and wife Jane, and his sister-in-law Judy Leafdale. John also had many nieces and nephews. Three sisters and one nephew preceded him in death. The family asks that memorial contributions be made to KMFA radio in Austin, Texas.

\section{Twin Research Reviews}

\section{Cognitive Skills and Social Mobility}

It is well known that more successful parents have more successful children, but the causal factors and processes have been a matter of debate. Specifically, to what extent do relatively advantaged children show upward social mobility due to (1) the opportunities presented to them by their families, (2) their genetically influenced interests and abilities and/or (3) a 
combination of the two? An interdisciplinary research team from the University of Minnesota and University of Edinburgh investigated these questions using twins and their parents who participated in the Minnesota Twin Family Study (McGue et al., 2020). The sample included 2594 twin offspring (52.6\% of whom were female), 1321 mothers and 1209 fathers. Education was coded as the highest degree completed on a 1-5 scale; occupation was coded according to the 7-point Hollingshead system and cognition was assessed with a short form of the Wechsler intelligence scales. A noncognitive composite score was derived from personality measures of the Multidimensional Personality Questionnaire. A polygenic score, based on findings from a large genome-wide association study, was calculated for educational attainment.

Many analyses are presented in this article, but the key findings were that children scoring over 1 standard deviation higher than their parents on both the cognitive and noncognitive measures either showed higher social standing than their parents or did not drop down. Parents' level of education did not affect the relationship between children's skills and mobility - this suggests that low-skilled children from advantaged homes were not buffered against downward social movement. The authors concluded that genetic factors, as well as cognitive and noncognitive abilities, influence the reordering of social standing across generations.

\section{Heritability of Selected Dental Traits}

An international research team addressed issues and practices regarding human crown morphology, namely (1) the relative heritability estimates of deciduous teeth (primary teeth) and adult teeth and (2) the nature of common assumptions underlying data collection and analysis (Paul et al., 2020). I will focus on the first question. Data were gathered from longitudinal dental casts of twins and families in Australia, offering a unique research advantage. Specifically, access to information gathered from the same individuals over time allowed assessment of the widespread assumption that deciduous teeth offer a 'clearer genetic signal' than adult teeth, due to reduced environmental influence on dental form. The majority of human crown characters evidenced moderate heritability, although variation across measures was evident. However, a lack of support was found for the hypothesis that deciduous teeth show greater genetic effects than adult teeth.

\section{Risk of Subarachnoid Hemorrhage}

The relationship between smoking and subarachnoid hemorrhage (SAH) is of great significance to good health and medical care. SAH involves bleeding in the space between the brain and the surrounding membrane (Mayo Clinic, 2020). A Finnish study examined the origin of SAH in twins from the older Finnish Twin Cohort, between 1976 and 2018 ((Rautalin et al., 2020). Lifestyle and other risk factors in twins discordant for SAH were of particular interest. The sample included 116 twin pairs discordant for SAH (25 of whom were monozygotic) and 2 twin pairs concordant for SAH who had succumbed to the condition. Across the cohort, smoking was related to an elevated risk for $\mathrm{SAH}$, regardless of whether the individual smoked occasionally or at the time of the study. This association was also found within smoking-discordant twin pairs, among both males and females and among monozygotic and dizygotic twins. It was concluded that smoking plays a causal role in SAH.

\section{Twin-to-Twin Transfusion Syndrome}

Researchers in Japan examined neurodevelopmental difficulties in 3-year-old twins who had received laser surgery in utero for twin-to-twin transfusion syndrome (TTTS) (Matsushima et al., 2020). They pointed out that such data are scarce, but important to review - that is because cerebral palsy and other neurodevelopmental problems have been identified in twins who had undergone prenatal laser surgery for TTTS, but such follow-up data have not been available for 3-year-old children. The study sample was comprised of 188 children from 110 twin pregnancies. Neurological characteristics were evaluated by the Kyoto scale, with difficulties defined as cerebral palsy, bilateral blindness, bilateral deafness or a developmental quotient of less than 70; a corrected age of 3.5 years was used. Brain magnetic resonance imaging (MRI) was also performed at the equivalent age.

Neurodevelopmental problems were observed among $8.5 \%$ of the cases, with cerebral palsy observed in six cases, or $3.2 \%$. None of the twins showed blindness or deafness. MRIs revealed abnormal brain findings in $56 \%$ of the children, including those with cerebral palsy. An earlier gestational age was associated with a higher incidence of neurodevelopmental difficulties.

\section{Media Reports}

\section{Identical Twins with Different Health Histories}

A father of a pair of identical male twins, Dr Amit Majmudar, composed a moving and informative essay on his sons' discordance for development of the heart (Majmudar, 2020). Dr Majmudar is a radiologist who monitors fetal heartbeat as part of his practice. He explained that one of his twins (Twin B) appeared to be growing normally in utero, while the other twin (Twin A) lacked a connection between his heart and his lungs, so would be unable to oxygenate blood. After birth, Twin A underwent a series of open-heart surgeries to repair the hole in his heart and to create an artificial pulmonary artery. There were complications and Twin B's physical activities at age 3 were severely limited. The twins are now preteens and, as their father points out, they are genetically identical but biologically different. He is providing his affected son with as many behavioral and physical resources as he can. The twins are a classic example of how adverse prenatal events can disrupt genetically influenced developmental programs.

\section{Twins Born 97 Days Apart}

It is likely that the November 17, 2018 birth of a fraternal twin female. Twins, Leonie and Liana, have set a new world record for the longest interval between twin deliveries (Larbi, 2019; Twinmom.com, 2020). The twins were born at the Holweide Hospital in Cologne, Germany. The twins' mother went into labor at 26 weeks, giving birth to Liana 3 months before her twin sister. Sister Liana weighed just 2 pounds at the time. After the first twin was delivered, the mother's cervix closed, allowing the second twin, who was attached to a separate placenta, to remain in the womb. The second twin, Leonie, was born 97 days later, on February 22, 2018, 4 days after their mother's expected due date. As of April 2019, both twins weighed 12 pounds. It was noted that the hospital had previously delivered other twins on different days. According to Larbi, the previous record was held by twins in Ireland, born 87 days apart. 


\section{Retiring Twin Tennis Players}

Identical twins, Bob and Mike Bryan, are the most successful male tennis team in history (Clarey, 2020). Their athletic career, which began in their early twenties, includes 16 Grand Slam titles in 30 finals and 119 tour titles. In 2012 and 2013, the twins held all four major titles and an Olympic gold medal. They were ranked as the number one team for 438 weeks and ended 10 seasons as the topranked doubles team. In August 2020, at age 42, the twins announced their decision to retire. They explained to the public that they relish competition, but the physical demands of playing and recovering have become difficult. They will, however, continue to play exhibition games.

\section{TikTok and YouTube Twins}

In April 2019, Alan and Alex Stokes were charged with a felony for staging a prank involving a bank robbery in Irvine, California (BBC, 2020). These identical twins were creating a video in which they appear to be running from a building, wearing masks and holding bags containing dollar bills. The twins asked bystanders for help in the way of clothes and rides, but they were refused. An Uber driver at the scene who was unaware of the prank asked them to leave his car. The police were called by a witness to these events - when the police arrived, they held the Uber driver at gunpoint, then released him. It turned out that the twins were making the film in order to attract attention on YouTube where they planned to post it. The twins also make videos for TikTok.

Some identical twins have been known for their lives of crime, such as Ronald and Reginald Kray of Great Britain (Morton, 2015). The Stokes twins were charged, given that they had staged two previous bank robberies for which they had received severe warnings.

\section{Twin Reality Stars}

Identical twins Nikki and Brie were the stars of the reality television show Total Bellas (Bluestone, 2020; Davison, 2020). They are Mexican-Italian in descent and were raised on a farm in Arizona. The twins relocated to Los Angeles, California in 2005 and began auditioning for television shows while working as models and servers. They became noticed when the actor Freddy Prinz Jr. created an on-stage maneuver for them in which the twins traded places while tricking the audience into believing that only one person was performing. They kept their twinship a professional secret for 2 months, after which they were cast in Total on E! in 2013, and in Total Bellas in 2016. Nikki and Brie were scheduled for induction into the WWE Hall of Fame in April 2020, but the event was postponed due to the COVID-19 pandemic. Both twins are now retired and pregnant and living next door to one another. They claim that there is a 'zero property line' between their homes, testimony to the close connection between these twin sisters.

\section{References}

BBC. (2020, August 6). TikTok twins charged over bank robbery 'prank'. BBC News. https://www.bbc.com/news/technology-53681018

Bluestone, G. (2020, July 23). Reality-Show Twins Conquer Quarantine. New York Times. D6.

Bouchard, T. J., Jr., \& Loehlin, J. C. (2001). Genes, evolution, and personality. Behavior Genetics, 3, 243-273.

Clarey, C. (2020, August 27). The Bryan Brothers call it a career, together. New York Times, B8.

Davison, T. (2020, August 6). TikTok twins Alan and Alex Stokes charged with felony after bank robbery prank. Mirror. https://www.mirror.co.uk/3am/ celebrity-news/tiktok-twins-alan-alex-stokes-22479380.

Larbi, M. (2019, April 17). Twin-credible: twins born 97 days apart in different years hailed a 'Medical sensation'. The Sun. https://www.thesun.co.uk/ fabulous/8882735/twins-born-97-days-apart/.

Loehlin, J. C. (2002). The IQ paradox: Resolved? Still an open question. Psychological Review, 109, 754-758.

Loehlin, J. C. (2004). Latent variable models: An introduction to factor, path, and structural equation analysis (4th ed.). Erlbaum.

Loehlin, J. C. (2010a). Verses of a young man. Copyright $\odot$ John C. Loehlin.

Loehlin, J. C. (2010b). Verses from later years. Copyright $\odot$ John C. Loehlin.

Loehlin, J. C., \& Martin, N. G. (2000). Dimensions of psychological masculinity-femininity in adult twins from opposite-sex and same-sex pairs. Behavior Genetics, 30, 19-27.

Loehlin, J. C., \& Nichols, R. C. (1976). Heredity, environment, and personality: A study of 850 sets of twins. University of Texas Press.

Majmudar, A. (2020, August 10). Identical twins with two very different destinies. New York Times. https://www.nytimes.com/2020/08/10/parenting/ infant-congenital-heart-defect.html? referringSource=articleShare.

Matsushima, S., Ozawa, K., Sugibayashi, R., Ogawa, K., Tsukamoto, K., Miyazaki, O., ... Sago, H. (2020). Neurodevelopmental impairment at three years of age after fetoscopic laser surgery for twin-to-twin transfusion syndrome. Prenatal Diagnosis, 40, 1013-1019.

Mayo Clinic. (2020). Subarachnoid hemorrhage. https://www.mayoclinic.org/ diseases-conditions/subarachnoid-hemorrhage/symptoms-causes/syc20361009

McGue, M., Willoughby, E. A., Rustichini, A., Johnson, W., Iacono, W. G., \& Lee, J. J. (2020). The contribution of cognitive and noncognitive skills to intergenerational social mobility. Psychological Science, 31, 835-847.

Morton, C. (2015, August 30). Legend: An in-depth look into the violent history of Ronnie and Reggie, the Kray twins. Independent. https://www.independent. co.uk/arts-entertainment/films/features/legend-depth-look-violent-historyronnie-and-reggie-kray-twins-10478174.html.

Paul, K. S., Stojanowski, C. M., Hughes, T. E., Brook, A. H., \& Townsend, G. C. (2020). Patterns of heritability across the human diphyodont dental complex: Crown morphology of Australian twins and families. American Journal of Physical Anthropology, 172, 447-461.

Rautalin, I., Korja, M., \& Kaprio, J. (2020). Smoking causes fatal subarachnoid hemorrhage: A case-control study of Finnish twins. Stroke, 1, 3018-3022.

Segal, N. L. (2012). Born together reared apart: The landmark Minnesota Twin Study. Harvard University Pre ss.

Segal, N. L., \& Montoya, Y. S. (2018). Accidental brothers: The story of twins exchanged at birth and the power of nature and nurture. St. Martin's Press.

Twinmom.com. (2020). These twin girls were born 97 days apart — in different years! https://twinmom.com/these-twin-girls-were-born-97-days-apart-indifferent-years/

Waldman, I., \& Turkheimer, E. (2014). Introduction to a Festschrift for John Loehlin. Behavior Genetics, 44, 547-548.

Woodstock School. (2020). Woodstock School. https://www.woodstockschool.in/ 